\title{
The Relationship between Parental Physical Affection and Child Physical Aggression among Japanese Preschoolers
}

\author{
Emiko Katsurada* \\ Kwansei Gakuin University
}

\begin{abstract}
The present study, based on Tiffany Field's model of violence and intimacy as well as other previous research, examines the relationship between parents' physical affection and their child's aggressive behavior. One hundred seventy-five mothers and 124 fathers of Japanese preschoolers answered a questionnaire that included a parental physical affection scale developed for this study. Children's aggressive behaviors were rated by their teachers on the hostile-aggressive subscale of the Preschool Behavior Questionnaire. Consistent with Field's model and previous studies, the results of logistic regression analyses indicated that children who received more physical affection from mothers or fathers during daily parenting were less likely to be aggressive at preschool. When the mother's and the father's physical affection scores were simultaneously entered in the equation, only the father's score was significant. Implications and limitations of the research are discussed.

Keywords : mother's physical affection, father's physical affection, parental physical affection, preschool children, child aggression, logistic regression
\end{abstract}

Childhood aggression manifested as bullying and school violence is a social problem in Japan. Aggressive behaviors are thought to originate in early childhood (Broidy, Nagin, Tremblay, Bates, Brame, Dodge, et al., 2003; Tremblay, Nagin, Séguin, Zoccolillo, Zelazo, Boivin, et al., 2004) and its presumed association with parenting is frequently mentioned in the literature. It has been reported that harsh or coercive parenting directly and/or indirectly relates to a high level of child aggression (Patterson, 1982; Herrenkohl \& Russo, 2001; Brook, Zheng, Whiteman, \& Brook, 2001; Chang, Schwartz, Dodge, \& McBride-Chang, 2003; Heidgerken, Hughes, Cavell, \& Willson, 2004; Henderson, 2008; Xu, Farver, \& Zhang, 2009; Brotman, O’Neal,

* Corresponding Author: Emiko Katsurada, Professor, Kwansei Gakuin University, 1-155 Uegahara Ichiban-cho, Nishinomiya, 662-8501, Japan. E-mail: katsurada@kwansei.ac.jp
Huang, Gouley, Rosenfelt \& Shrout, 2009).

Association between positive parenting and children's less aggressive behaviors is also reported, though less frequently. For example, Brotman et al. (2009) examined the effectiveness of family intervention and showed that improvement in responsive parenting, such as praise, affection and responsiveness during a parent-child play is linked to a child's less aggressive behaviors toward the parent. Another study indicated that maternal affection is related to toddlers' low level of aggression (Brook et al., 2001).

Other studies suggest that there are positive effects of skin-to-skin (Kangaroo) care on infants' physical development (e.g., Charpak, Ruiz-Peláez, Figueroa de C., \& Charpak, 2001). Kangaroo care also has positive effects on infants' behavioral organization and emotion regulation (Feldman, Weller, Sirota, \& Eidelman, 
2002).

Regarding child aggression, Main and Stadtman (1981) showed that mothers who disliked physical contact with their babies in the first quarter of life were more likely to have more aggressive and angry babies in the last quarter of the first year. But the positive effect of physical contact is not limited to infancy. Field $(1999 \mathrm{a} ; 1$ 1999b) found an association between touch and aggression among preschoolers and adolescents in a cross-cultural comparison.

In her study of preschoolers, Field observed preschoolers' interactions with their parents and peers on playgrounds, and found that American children were touched less by their parents and were more aggressive toward their parents and peers than French children (Field, 1999a). Parallel results were identified among adolescents, including research in which French adolescents showed more affectionate touching and more positive verbal and physical behaviors in peer interactions than did their American counterparts (Field, 1999b).

Based on these studies, Field (2002a) developed a model that suggests children/ adolescents become aggressive in part because they lack intimacy with peers and parents or other adults. Subsequently, she and her colleagues carried out a massage therapy intervention and reported that aggressive adolescents who received massage therapy decreased hostility and aggressiveness compared to their counterparts who received relaxation therapy (Diego et al., 2002).

Field (2002a) suggested the difference in response was due to a reduction of dopamine level and an increase of serotonin level as a result of massage therapy effects on aggression. Based on the compelling results of massage therapy on children's aggression, Field and her colleagues (1994; 2002b) advocates more positive physical touch in nurseries and preschools.

Reviewing studies on massage (touch) therapy, Blackwell (2000) also concluded that although touch therapy should not be considered as a panacea, positive tactile stimulation is one of the most essential elements in the nurturing and healing environment of the children.

Thus, taken together, western literature clearly shows positive effects of parental touch on children's aggression. In Japan, however, such positive effect is not so clearly shown in literature, although it is theoretically acknowledged.

In Japan, the word "skinship" is derived from English words of "skin" and "-ship." It represents the positive connotation associated with physical contact. Although many Japanese researchers and educators emphasize the importance of "skinship" on a child's development of social competence and encourage "skinship" in parenting (Hirai, 1980; Koseki, 1997; Misago, 2004; Yamamura, 1982; Yamaguchi, 2003a, 2004), empirical studies to support their proposition are scarce and to date researchers have only examined children's aggression with respect to parenting styles and attitudes (Nakamichi \& Nakazawa, 2003; Nakadai, Kanayama, \& Maeda, 2004). These studies, however, do not provide direct support for the positive effect of physical contact ("skinship") in parenting.

There is only one empirical study regarding parental physical contact and child's aggression that was published in Japan in which Yamaguchi (2003b) found a negative correlation between maternal physical contact in infancy and aggressive personality among adolescent girls. That study, however, examined only girls and utilized mothers' retrospective memories to measure positive physical contact with her child, an approach that may be less accurate than using concurrent measurement. Yamaguchi's study also examined only mothers' physical affection but not that of fathers.'

Generally, mothers' and fathers' interaction patterns with their children are different; mothers typically take care of children during their daily routine (i.e. dressing, eating, and bathing) as well as play with them, whereas fathers' interactions with their children occur mostly in play situations (Barton \& Ericksen, 1981; Tulananda $\&$ Roopnarine, 2001). Therefore, examining not only mothers' physical affection but also that of fathers would be very important. Furthermore, 
since parents generally touch preschool aged children less often than infants and toddlers (Field, Harding, Soliday, Lasko, Gonzalez, \& Valdeon, 1994; Mogi 2003), it is important to investigate the discrete effect of physical contact among preschoolers.

The present study focuses on the positive aspect of parenting by measuring physical affection from mothers and fathers in the context of child-rearing behaviors and investigates its association with preschoolers' aggressive behaviors in a sample of Japanese boys and girls. Based on Field's model (2002a) and other aforementioned studies, it is hypothesized that young children who receive more physical affection from their parents at home are less likely to show aggressive behaviors at preschool. If the hypothesized association is found, this study could be an important contribution toward helping to reduce bullying and school violence, which are social problems in Japan.

\section{Method}

\section{Participants}

One hundred seventy-five mothers and 124 fathers of children attending three preschools in Akita City and the children's teachers participated in this study. Only children over age four were chosen for this study, since three years olds still require comparatively more parental physical care in the course of daily routines such as feeding, dressing, and bathing.

Just over half $(55 \%)$ of the children were boys. Mothers' and fathers' average ages were 34.5 and 36.5 years respectively, with a range of 25 to 50 years. All of the fathers worked full-time while approximately half of the mothers either had a full or part time job and the other half were not employed outside the home.

Most of the families were two-parent families (93.7\%) and 6.3\% (11 mothers) were singleparents. The average number of children in each family was two, ranging from one to four. Approximately $60 \%$ were nuclear families and $40 \%$ were extended families in which adults other than the child's parents lived in the house.

All participants resided in Akita City, the capital of Akita prefecture located in the northern part of Japan, population 320,000.

\section{Measures}

Levels of parental physical affection and child aggression were assessed by means of a self-reported and a teacher-reported measurement respectively. The two instruments are described below.

Parental physical affection. To assess mothers' and fathers' physical contact with a targeted child during parenting, a questionnaire was developed specifically for this study. The questionnaire consisted of 20 short sentences that describe affectionate caring and child-caregiver interactive behaviors involving positive physical contact, most of which were modeled after a previous study of maternal affectionate parenting behaviors (Sano, Hagino, \& Suzuki, 1994). All items describe parenting behaviors involving positive physical contact, such as, "You bathe with your child," "You comb your child's hair," "When you play with your child, you tickle him/her," "You kiss your child," and so on. Mothers and fathers were asked to respond to the statements on a 4-point frequency scale ranging from 1 (never do this) to 4 (always do this). A higher score means more physical affection (more touching) toward the child in daily parenting.

To verify the structure of the newly developed measurement, we conducted factor analyses of the mother' and the father's data separately. Based on the results of the analysis, 12 items consisting of two factors were selected for the mother's physical affection scale and 13 items consisting of two factors were selected for the father's physical affection scale. Cronbach's alphas for those scales were .79 and .85 respectively.

Child aggression. The Preschool Behavior Questionnaire (PBQ; Behar \& Stringfield, 1974) was used to measure each child's aggressive 
behaviors. With permission from Dr. Behar, the author translated the PBQ into Japanese. The Japanese items were then back-translated into English by a bilingual American to assure that the original English meanings were kept. Then, the Japanese items were checked by two preschool teachers who were not involved in this study, and minor modifications for fluency of expression were made without changing any meaning.

The children's teachers were asked to answer the Japanese version of the PBQ individually for every child in their classes (average number of 30) using a 3 -point scale: $0=$ never present, $1=$ sometime present, and 2 = always present. The PBQ has three subscales: hostile-aggressive (Scale 1), anxious-fearful (Scale 2), and hyperactive-distractible (Scale 3 ). To verify the subscale structure for the Japanese version, a factor analysis was conducted. The result confirmed the original three subscales; ten out of 11 items of the original hostile-aggressive subscale were loaded more than .35 to Factor 1, seven out of nine items of the original anxious-fearful subscale were loaded more than .35 to Factor 2, and three out of four items of the original hyperactive-distractible subscale were loaded more than .40 to Factor 3 . The total score of the original hostile-aggressive subscale was then used as the child's aggressive score in the present study. Items included in this subscale, for example, were "Destroys own or others' belongings," "Fights with other children," and "Doesn't share toys." This subscale measures only physical aggression of children. Cronbach's alpha for this subscale was .88 .

\section{Procedure}

One preschool from three different areas (northern, central, and southern parts) of the city was randomly selected. The author contacted the headmaster of each preschool, visited him/her to explain the purpose of the study and the process of the data collection, and asked him/her to participate in the study. When the headmaster agreed to participate, his/her preschool was selected. When the headmaster did not agree, another preschool in the same area was solicited for participation. This process was repeated until one preschool in each area was selected. In most cases, headmaster's agreement was obtained on the first or second attempt.

Questionnaires about parental physical affection and demographics were distributed to the parents, and completed questionnaires were collected through the preschool teachers. During the same period, the teachers completed the PBQ for each child in their classrooms. Data collection was conducted in the middle of the second semester of preschool; therefore, the teachers had known the children in their classroom for at least six months or more. The average length of time that teachers had known the children was 8.42 months.

\section{Results}

Prior to conducting the main analysis, relationships between parental physical affection scores or children's aggressive scores and demographic variables were examined. The results of the preliminary analyses are presented first below, followed by the primary findings.

Preliminary analyses of parents' physical affection scores and children's aggression scores. In two parent households, mother's and father's physical affection scores were correlated $(r=.36$, $p<.01)$. In both two-parent and single-parent households, mother's physical affection score was negatively correlated with her child's age ( $r$ $=-.15, p<.05)$ and the number of children in the family $(r=-.31, p<.01)$. In particular, when the target child had younger siblings, the mother's physical affection score was significantly lower $(M=36.61, S D=5.75)$ than for those of children without younger siblings $(M=38.71, S D=5.09)$, $t(167)=2.51, p<.05$. However, such correlations and differences were not found for the father's score.

Furthermore, in both two-parent and singleparent household, mother's and father's physical affection scores did not differ significantly depending on the child's gender, the parent's age 


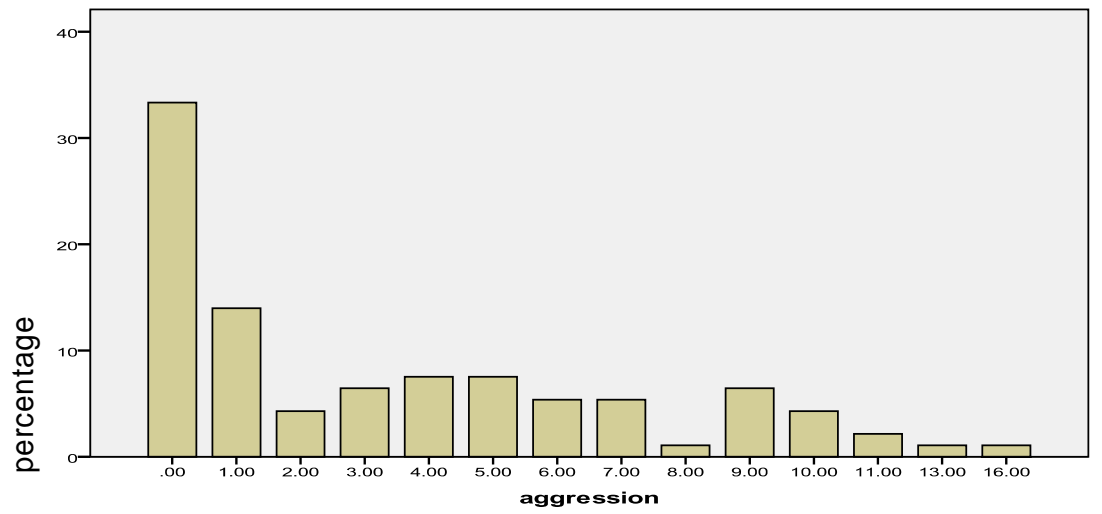

Figure 1a. Distribution of boys' aggression score

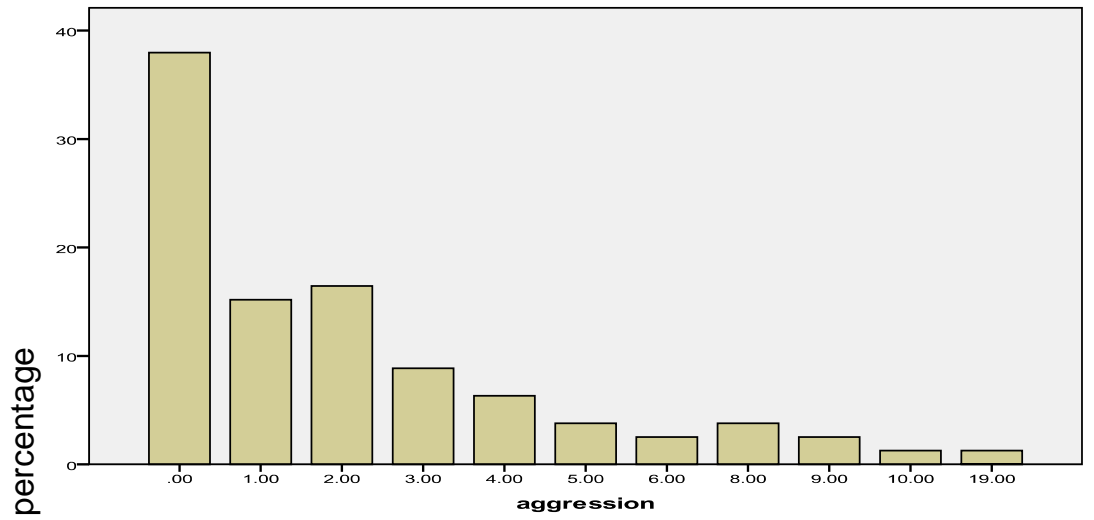

Figure 1b. Distribution of girls' aggression score

or the mother's employment status. However, single mothers' physical affection scores $(M=$ $40.70, S D=3.71)$ tended to be higher than those of mothers from two-parent family $(M=37.60$, $S D=5.52), t(167)=-1.74, p<.10$.

Children's aggression scores were examined for association with demographic variables. There was a significant gender difference between boys' score $(M=3.44, S D=3.77)$ and girls' $(M=2.24, S D=3.15), t(170)=2.24, p$ $<.05$. For both genders, children's aggression scores were highly skewed (see Figure 1a \& 1b). As a result, it was expected that parental physical affection would be related to children's extreme aggression. Based on this expectation, children were divided into two groups, with children having scores above the $90^{\text {th }}$ percentile identified as aggressive. Since there was a gender difference in the children's aggression scores, $90^{\text {th }}$ percentile scores were calculated separately for boys and girls. Those who scored higher than 9 points for boys and 7 points for girls were placed in the aggressive group category ( 7 girls and 14 boys), and the remainder were placed in the non-aggressive group.

Chi-square analyses indicated no association between children's aggressive status and their family structure (nuclear vs. extended family and single mother vs. two parents), nor with the mother's employment status or the number of 
children in the family. Children's aggression status, however, did correlate to their age (given in months): the aggressive group was significantly younger $(M=62.24, S D=5.05)$ than the non-aggressive group $(M=65.64, S D=$ $6.75), t(172)=2.76, p<.01$.

Relationships between parental physical affection and child's aggression. To examine the relationship between parents' physical affection and children's aggression, logistic regression analyses were conducted with the child's aggressive status as the dependent variable.
Three logistic regression analyses were run: first with the mother's physical affection score as a predictor variable, second with the father's physical affection score as a predictor variable, and then with the mother's and the father's scores together as predictor variables. Child's age and gender were included as control variables. Means and standard deviations of the independent variables are shown in Table 1.

Both mother's physical affection score and father's physical affection score were significantly related with the child's aggression (see Table 2 and 3). Controlling for the child's

Table 1

Means and Standard Deviations of Independent Variables

\begin{tabular}{lll}
\hline \multicolumn{1}{c}{ Variables } & & M (SD) \\
\hline Child's age (in month) & $\mathrm{n}=175$ & $65.21(6.71)$ \\
Mother's physical affection & $\mathrm{n}=170$ & $37.80(5.56)$ \\
Father's physical affection & $\mathrm{n}=121$ & $34.60(6.70)$ \\
\hline
\end{tabular}

Table 2

Logistic Regression: Mother's Physical Affection Score as a Predictor

\begin{tabular}{lccc}
\hline \multicolumn{1}{c}{ Variables } & $\beta$ & $(\mathrm{SE})$ & Odds Ratio \\
\hline Child's age & -.11 & $(.04)$ & $.90^{*}$ \\
Child gender & .66 & $(.52)$ & 1.94 \\
Mother's affection & -.10 & $(.05)$ & $.90 *$ \\
Cox and Snell $\mathrm{R}^{2}$ & & .07 & \\
\hline
\end{tabular}

Note. Dependent variable: $0=$ non-aggressive, $1=$ aggressive

$* \mathrm{p}<.05$

Table 3

Logistic Regression: Father's Physical Affection Score as a Predictor

\begin{tabular}{lccc}
\hline \multicolumn{1}{c}{ Variables } & $\beta$ & $(\mathrm{SE})$ & Odds Ratio \\
\hline Child's age & -.11 & $(.05)$ & $.89^{*}$ \\
Child gender & .29 & $(.55)$ & 1.34 \\
Father's affection & -.09 & $(.04)$ & $.91^{*}$ \\
Cox and Snell $\mathrm{R}^{2}$ & & .08 & \\
\hline
\end{tabular}

Note. $0=$ non-aggressive, $1=$ aggressive

$* \mathrm{p}<.05$ 
The Relationship between Parental Physical Affection and Child Physical Aggression among Japanese Preschoolers

Table 4

Logistic Regression: Mother's and Father's Physical Affection Scores as Predictors

\begin{tabular}{lccc}
\hline \multicolumn{1}{c}{ Variables } & $\beta$ & (SE) & Odds Ratio \\
\hline Child's age & -.12 & $(.05)$ & $.89^{*}$ \\
Child gender & .34 & $(.55)$ & 1.40 \\
Mother's affection & -.07 & $(.05)$ & .93 \\
Father's affection & -.09 & $(.04)$ & $.92^{*}$ \\
Cox and Snell ${ }^{2}$ & & .10 & \\
\hline
\end{tabular}

Note. $0=$ non-aggressive, $1=$ aggressive

$* \mathrm{p}<.05$

age and gender, children who received more physical affection from their parents were less likely to be in the aggressive group (odds ratio $=.90$ for maternal affection, and .91 for paternal affection).

When the mother's and father's physical affection scores were simultaneously entered in the equation as independent variables, however, only the father's score was significant (see Table 4). Thus, controlling for the mother's physical affection, father's physical affection is related to a child's aggressive status. However, the mother's physical affection is not related to a child's aggressive status when the father's physical affection was controlled.

\section{Discussion}

Although a number of studies have been conducted to explore the relationship between affectionate parenting styles and children's behavioral problems, few studies focus on physical contact in parenting, especially in Japan. The present study was designed to examine the relationship between parents' physical affection and child's physical aggression among Japanese preschoolers. Consistent with the results of previous studies of Field $(1999 \mathrm{a} ; 1999 \mathrm{~b})$ and Yamaguchi (2003b) as discussed above, the present study found that children who had more positive physical contact from their mothers and fathers at home were less likely to be rated as extremely aggressive by their teachers. Moreover, father's physical affection rather than mother's was related to the less child aggression.

As suggested by Field (2002a), some forms of tactile stimulation, such as touch that children receive through daily parenting might have some effects on reducing physical aggression. However, since the present study is not a longitudinal study, it is possible that a child's aggressiveness makes parents less physically affectionate.

As mentioned in the introduction, early childhood aggression is a possible origin of bullying and school violence. The results of the present study showing the relationship between more parental physical affection and less child aggression suggest that affectionate parenting with a lot of positive physical contact during the preschool period may help reduce bullying and school violence in the later period.

The preliminary analyses of data from this study showed that older children were touched less frequently by their mothers, a finding which is consistent with the previous studies. Results also showed that children who had younger siblings were not touched as frequently by their mothers. This result may be explained by the fact that since younger children require more care involving physical contact, mothers' physical contact would concentrate on younger children in a family as well as the expectation that older children would be more independent. However, the degree of fathers' physical contact with their children was not affected by such variables. As mentioned above, previous studies have 
indicated the parents' different interaction patterns with children; fathers' interaction takes place primarily during free play situations rather than in the course of activities of daily living, therefore, children's age and the existence of younger siblings do not have strong impact on fathers' degree of physical contact with children.

Considering the different interaction patterns with children between mothers and fathers, the present result suggests that physical affection in play situations would be more effective in reducing child's aggression since fathers' physical affection rather than mothers' was related to child's aggressive status.

The results of the present study provide empirical support for Field's model as well as for Japanese educators and researchers who advocate "skinship" in parenting. Parents who have aggressive preschoolers should try to have more positive physical contact ("skinship") with their children in their parenting. In particular, "skinship" in play situations might be an effective means to mitigate aggressive behavior.

At the same time, it is important to recognize the limitations in this study. First, parents' physical affection was measured by a self-evaluated and self-reported questionnaire. To overcome this limitation, a more objective measure, such as additional observation of parent-child interaction during play situation and daily parenting should also be included in a future study.

A second limitation is that this study was cross-sectional and examined only preschoolers. Therefore, the long-lasting effect of parental physical affection at the preschool period is not known. Future research should examine extended developmental periods using a longitudinal research design. Whether the beneficial effects of parents' physical affection in early childhood would have long-lasting effects until middle childhood is of great interest and has important implications for early childhood parenting.

In spite of its limitations, this is one of only a few empirical studies in Japan that demonstrates the relationship between aggression in young children and their parents' physical contact in daily parenting. Also, the result of the present study that the father's physical contact in daily parenting rather than the mother's related to their child's aggression is a significant new finding in this area of study and warrants further investigation.

Acknowledgments: The author would like to thank the headmasters, teachers, and parents who participated in this study. I also wish to thank Chikako Sekiya for helping data collection and Maureen Lynch for editing the manuscript. The author's appreciation extends to the anonymous reviewers' comments on the first manuscript.

\section{References}

Barton, K., \& Ericksen, L. K. (1981). Differences between mothers and fathers in teaching style and child-rearing practices. Psychological Reports, 49, 237-238.

Behar, L., \& Stringfield, S. (1974). The preschool behavior questionnaire. In $\mathrm{J}$. V. Mitchell, Jr. (Ed.), The ninth mental measurements yearbook. Lincoln: University of Nebraska Press.

Blackwell, P. L. (2000). The influence of touch on child development: Implications for intervention. Infants and Young Children, 13, 25-39.

Broidy, L. M., Nagin, D. S., Tremblay, R. E., Bates, J. E., Brame, B., Dodge, K. A. et al. (2003). Developmental trajectories of childhood disruptive behaviors and adolescent delinquency: A six-site, cross-national study. Developmental Psychology, 39, 222-245.

Brook, J. S., Zheng, L., Whiteman, M., \& Brook, D. W. (2001). Aggression in toddlers: Associations with parenting and marital relations. The Journal of Genetic Psychology, 162, 228-241.

Brotman, L. M., O’Neal, C. R., Huang, K., Gouley, K. K., Rosenfelt, A. R., \& Shrout, P. E. (2009). An experimental test of parenting practices as a mediator of early childhood physical aggression. Journal of Child 
Psychology and Psychiatry, 50, 235-245.

Chang, L., Schwartz, D., Dodge, K. A., \& McBride-Chang, C. (2003). Harsh parenting in relation to child emotion regulation and aggression. Journal of Family Psychology, 17, 598-606.

Charpak, N., Ruiz-Peláez, J. G., Figueroa de C. Z., \& Charpak, Y. (2001). A randomized, controlled trial of Kangaroo Mother Care: Results of follow-up at 1 year of corrected age. Pediatrics, 108, 1072-1079.

Diego, M. A., Field, T., Hernandez-Reif, M., Shaw, J. A., Rothe, E. M., Castellanos, D., \& Mesner, L. (2002). Aggressive adolescents benefit from massage therapy. Adolescence, 37, 597-607.

Feldman, R., Weller, A., Sirota, L., \& Eidleman, A. I. (2002). Skin-to-skin contact (Kangaroo care) promotes self-regulation in premature infants: Sleep-wake cyclicity, arousal modulation, and sustained exploration. Developmental Psychology, 38, 194-207.

Field, T. (1999a). Preschoolers in America are touched less and are more aggressive than preschoolers in France. Early Child Development and Care, 151, 11-17.

Field, T. (1999b). American adolescents touch each other less and are more aggressive toward their peers as compared with French adolescents. Adolescence, 34, 753-758.

Field, T. (2002a). Violence and touch deprivation in adolescents. Adolescence, 37, 735-749.

Field, T. (2002b). Infants' need for touch. Human Development, 45, 100-103.

Field, T., Harding, J., Soliday, B., Lasko, D., Gonzalez, N., \& Valdeon, C. (1994). Touching in infant, toddler, and preschool nurseries. Early Child Development and Care, 98, 113-120.

Heidgerken A. D., Hughes, J. N., Cavell, T. A., \& Willson, V. L. (2004). Direct and indirect effects of parenting and children's goals on child aggression. Journal of Clinical Child and Adolescent Psychology, 33, 684-693.

Henderson, S. H. (2008). Pathway to externalizing behavior: The effects of mothers' harsh parenting and toddler's emotional reactivity. Dissertation Abstract International,
68(9-B), 6308.

Herrenkohol, R. C., \& Russo, M. J. (2001). Abusive early child rearing and early childhood aggression. Child Maltreatment, 6, 3-16.

Hirai, N. (1980). Nyuyouji no seishineisei, 2: Boshi kanno shintai sesshoku [Infants and young children's mental health 2: Physical contact between mothers and children]. Shounika Shinryou, 43, 538-541.

Koseki, Y. (1997). Fureai Kosodateron: Shougai nyuyouji hoiku no jissen [An essay on touching parenting: A training program for handicapped children]. Tokyo: Chuo Houki.

Main, M, \& Stadtman, J. (1981). Infant response to rejection of physical contact by the mother. Journal of the American Academy of Child Psychiatry, 20, 292-307.

Misago, C. (2004). Souron: Fureru to iukoto [An essay: Touching]. Perinatal Care, 23, 10-13.

Mogi, S. (2003). Youjiki niokeru shintaisesshoku to jiritsu no jikitekikubun [Physical contact in the preschool period and age demarcation of independence]. Proceedings of the Meeting for Japan Society of Research on Early Childhood Care and Education, 192-193.

Nakadai, S., Kanayama, M., \& Maeda, K. (2004). Effects of mothers' attitudes for child rearing on problem behaviors in young children. Hiroshima University Journal of Psychology, 4, 151-157.

Nakamichi, K., \& Nakazawa, J. (2003). Maternal/paternal childrearing style and young children's aggressive behavior. Memoirs of Department of Education, Chiba University, 51, 173-179.

Patterson, G. R. (1982). Coercive family processes. Eugene, OR: Castalia.

Sano, R., Hagino, N., \& Suzuki, G. (1994). Boshikouryu nikansuru kenkyu: Skinship ni tuite [A study of the mother-child interaction: Regarding `skinship`]. Shouni Hoken Kenkyu, 54, 15-21.

Tremblay, R. E., Nagin, D. S., Séguin, J. R., Zoccolillo, M., Zelazo, P. D., Boivin, M., et al. (2004). Physical aggression during early 
childhood: Trajectories and predictors. Pediatrics, 114, 43-50.

Tulananda, O., \& Roopnarine, J. L. (2001). Mothers' and fathers' interactions with preschoolers in the home in northan Thailand: Relationships to teachers' assessment of children's social skills. Journal of Family Psychology, 15, 676-687.

Xu, Y., Farver, J. M., \& Zhang, Z. (2009). Temperament, harsh and indulgent parenting, and Chinese children's proactive and reactive aggression. Child Development, 80, 244-258.

Yamaguchi, H. (2003a). Aibu: Hito no kokoro ni fureru chikara [Caress: Power of touching human mind]. Tokyo: NHK Books.

Yamaguchi, H. (2003b). Nyujiki niokeru boshi no shintaisesshoku ga shourai no kougekisei ni oyobosu eikyo [Effect of mothers' touch in infancy on children's future aggressiveness]. The Japanese Journal of Health Psychology, $16,60-67$.
Yamaguchi, H. (2004). Kodomo no nou wa hada ni aru [A child's brain exists on skin]. Tokyo: Koubunsha.

Yamamura, K. (1982). Amae to jiritsu no setten wo kangaeru [Exploring the connection between 'amae' and independence]. Jido Shinri, 36, 791-795.

Received October 26, 2011

Revision Received January 6, 2012

Accepted January 15, 2012 